\title{
A Thematic Analysis of Preferences of Young People using Online Support to Discuss Suicide Ideation - UK
}

\author{
(C) 2013 Sally Evans
}

\begin{abstract}
Young people (mainly 15-17 years) using an online counselling, support and advice website were asked about their preferences for online versus face-to-face discussion of suicidal feelings. Thematic analysis of results $(n=24)$ yielded a main theme of 'anonymity' with sub-themes of 'safety and freedom', 'confidentiality' and 'control'. Issues of safeguarding distressed young people who have chosen to remain anonymous are raised.
\end{abstract}

\section{Key words}

Young People, Cyberspace, Anonymity, Suicide Ideation, Transactional Analysis

For confidentiality reasons, the usernames of the young people have been changed. Their quotes are in the original form with regard to spelling, grammar and punctuation. For the benefit of those for whom English is not a first language, a 'translation' into proper English of abbreviated/misspelled words is given in square brackets within the quotes.

\section{Introduction}

This article utilizes research carried out with a group of self-selecting young people who use the Internet counselling, support and advice website www.Kooth.com. They were asked about their preferences about talking about suicidal feelings online rather than face to face.

Previous research by King et al (2006), utilising Kids Helplin' (www.kidshelp.com.au), an Australian Young People's website, showed a preference for online communication, although by 2010 Kidshelpline (2011) showed that preferences had changed towards contact via telephone, and in particular mobile phone, when discussing suicide thoughts or behaviours. This change in contact preference occurred over seven years during which contacts regarding suicide ideation increased from $2.9 \%$ in 2006 to $6.4 \%$ in 2011 ; online support for discussing suicide ideation still accounted for $33 \%$ of the counselling sessions in 2010.

In the UK, Cooper's (2013) critical review and evaluation report of UK counselling in secondary schools, did report a preference for online support. He reported statistics from various researches ranging from as low as $8 \%$ up to $33 \%$ of young people who would 'probably' or might 'definitely' consult a face-to-face/school-based counsellor if they experienced an 'emotional difficulty'. These figures are comparable with research carried out by Childline (2008), which found that only $8 \%$ of 1,024 children surveyed would talk about a 'big' problem with an adult, with $54 \%$ citing they would feel 'too embarrassed' about this. In cyberspace, there is no such embarrassment, which may account for why $46 \%$ of secondary school children surveyed would look online for support (Cooper 2013).

Since the inception of the World Wide Web in 1991, and in particular since the interactive birth of Web 2.0 (1999), the Internet has become a pervasive feature of modern life. Where once online and offline lives were separate and distinctive, now that boundary has blurred. Online life now exists as part of real life and not something separate from it, and this is particularly true for many young people or "digital natives" (Turkle 2011 p.xii quoting Palfrey, J \& Gasser, U. 2008)) who are born of the digital age and are unaware of a life before its invention. Young people's access to the Internet at school, college and at home, together with their familiarity with communicating for pleasure, study and socializing, has naturally led to them using cyberspace to seek out emotional support. This has facilitated and encouraged the increased placing in cyberspace of young people's emotional and mental health support services, both in the form of counselling and self-help materials. For young people, cyberspace is always there, 
waiting, paying attention, listening and ready to offer support, validation feedback and much, much more. "most of us talk to friends online everyday, it's part of our lives, so even when chatting to a counsoler [counsellor] online, we not completely out of our comfort zone" Floyd, 17 years

\section{Adolescent Suicide}

Adolescent suicide is of international significance. Globally youth suicides are increasing (Befrienders Worldwide 2013) to such an extent that young people within the 15-19 years age group are now the group at the highest risk of suicide in a third of all developed and developing countries, with the 10-25 year age group being particularly vulnerable as suicide within this age group is the second biggest cause of death (World Health Organisation 2009). Globally, suicide for all age groups and gender, represents a death every 40 seconds and by 2020 the WHO predict this figure will have increased to one death every 20 seconds.

In the UK, after years of decline where the suicide rate fell by $28 \%$ between the years $1997-2003$, those rates have now increased for those in the 10-19 years age bracket to represent $4 \%$ of total UK suicides (Windfuhr et al 2008). Presumably these young people believed "the only way out" (Ayres 2006 p.4) was to kill themselves with hanging/strangulation and self-poisoning being the most common methods (Windfuhr et al 2008). More recent statistics issued by the Office of National Statistics (2011) have confirmed the downward trend has been reversed and suicides increased significantly in the UK between 2010 and 2011.

\section{Literature Review}

Adolescence is a time of significant developmental change. Erikson describes adolescence as the psychosocial stage of identity verses confusion, where exploration of independence, the development of a sense of self and personal identity together with social and peer relationships become paramount. In transactional analysis terms, Levin (1982) described adolescence as the stage of 'sex and separation' and Widdowson (2008) as "primarily a time for formation of script in the context of self and others ... [when] . . due to the plasticity of the brain" (p.141) the script can either be confirmed or re-written with a new show put on the road instead.

Cornell (2008) further discusses script renewal, confirmation of it and suicidal ideation. He writes, "script level change can create periods of severe stress, guilt, anxiety both intrapsychically and interpersonally" (p. 91). Therefore it would not be uncommon for adolescents, as a group who find themselves in the midst of such significant changes, to experience suicidal ideation.
Other than those authors mentioned above, Little (2009) and White (2011) have both written about suicide and Ayres (2006) has written specifically on suicide as it relates to young people: however there seems nothing within TA literature linking suicide, young people and cyberspace.

\section{Research Question}

Whilst I knew from previous research (King et al, 2006) that young people find the Internet a 'comfortable environment' to access counselling services, my aim in the research was to find out if that translated to discussing their suicidal ideation.

Discovering this would, I hoped, enable procedures to be developed which would support both the organisation and the therapeutic counsellors in their work with their young suicidal clients.

I believed that a piece of 'qualitative inquiry' held "the promise of discovery, of generating new insights into old problems" (McLeod 2001 p.1); it would generate ideas on how as practitioners we could help, what interventions we could use to support vulnerable young people, what questions we could ask at this distressing time, as Shneidman (1994), quoted by Leenars (2010) suggests: "The most important question to a potentially suicidal person is not an inquiry about family history or laboratory test of blood or spinal fluid, but "how do you hurt?" and "how can I help you?" (p.14)

\section{Methodology}

The method chosen was to ask the young people by posting a message on the three moderated public message boards on www.Kooth.com entitled "Help with my Studies??" I choose this method because I believed it would give me access to a large number of young people. I also knew from moderating the boards that there was already a number of young people discussing suicide and believed a simple post would enable them and any other young person to get involved if they chose to do so. The message I posted was thus:

$H i$,

I'm Sally and I manage the counsellors here on Kooth. I've just started a course and for it I have to do a piece of research. The research I'm interested in is young people's experience of talking online to a counsellor and whether young people prefer talking online rather than face-to-face. I'm particularly interested in talking about suicide online as I know this is often one of the hardest things to talk about and I wonder if it's easier online and if so why?

So why this post? Well I'm wondering if anyone out there would be interested in chatting to me? We could either do it in this thread or we could set up a private chat or messages. I'm happy with either. 
If anyone is interested or wants more info, please just message me. Thanks in advance

Sally

\section{Ethics}

My status as the researcher was that I was the manager of the online Therapeutic Team, which consists of trained and qualified counsellors and psychotherapists. I originally discussed this research with the Senior Management Team where permission to carry out the research was granted by the Managing Director. One of the concerns I had regarding asking young people to discuss suicidal ideation with me was the impact these discussions could have upon their emotional welfare and safety.

I subsequently discussed the research and the possible implications with the Therapeutic Team: first to ascertain whether they were working with any young people who they thought might be willing to contribute; second to alert them to the possibility that there may be an increase in suicide ideation 'talk' on the message boards and in 'chat'; and lastly to ascertain their thoughts regarding the research.

After discussions with the Therapeutic Team, and upon reflection, I decided that I would only 'accept' young people into the research who were either already engaged with a 'primary counsellor' or were 'known' to the Therapeutic Team by being ex-clients and/or regular users of the message boards. This I felt would also have the additional effect of discouraging those young people who may be less serious about the research. I was aware this might mean that some young people were excluded from the research for what I believed were "safety" reasons, although this precaution turned out not be needed.

\section{Respondents}

The post on the 3 separate message boards in a four week period (November 2010) received a total of 14 views on the school years 7, 8 and 9 board, (ages 1114); 121 views on the school years 10 and 11 (ages 1516) board and 134 views on the older (16+ years) boards. This was comparable with other posts on the message boards. No young person was excluded from taking part, as all young people were 'known' users of the service. There can be no guarantee, of course, that all the young people who might have wanted to take part felt able to respond to my message.

16 young women and 6 young men posted replies. Most of these young people fell within the 15-17 year age group. The youngest respondent was 14 years and the oldest respondent was 23 years. Most young people posted between one and three posts. Some young people sent me private messages and/or 'chatted' to me via the website's secure, synchronous chat room.

\section{Method}

Thematic analysis (Braun \& Clarke 2006) was used to identify, analyse and report patterns (themes) within the data. This was done by the author and supervision was provided, including by an experienced researcher, because this was part of a dissertation for a master's degree.

\section{Results}

An over-arching theme emerged of Anonymity, and within that sub-themes of Safety \& Freedom, Confidentiality, and Control of Affect \& Relationship. Figure 1 shows how these fitted below the theme of Preference that had been a key focus of the research question posed.

“..right id [l'd] personally say online is best .. when you are talking bout [about] thing you wouldn't normally like, suerside [suicide]..." SUnshiNe, 17 years

Figure 1: Themes and Sub-Themes

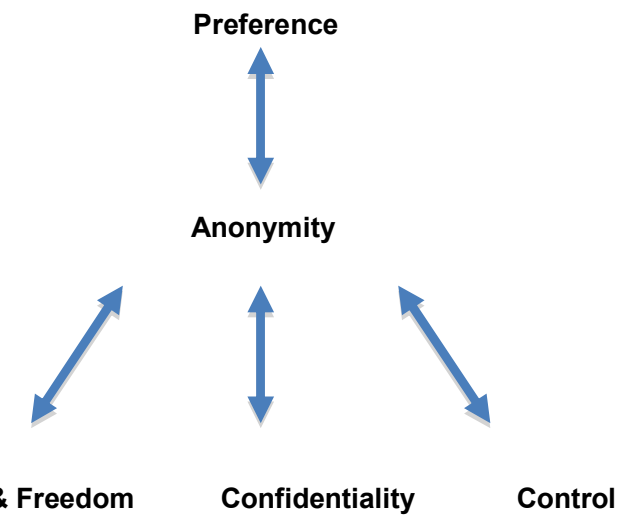

Anonymity

Anonymity was the major theme expressed by the young respondents and the bedrock upon which all other themes rested. Anonymity granted young people the safety and freedom to say all they needed to say with self-confidence and control.

"..it's just easier to reveal how broken you can be to someone who can't see you" ticktac, 15 years

"...Face to face they know you, on here they don't even know my name!" princess 14, 14 years

"ive recently tried committing suicide and $i$ wud [would] find it difficult telling a councellor [counsellor] face to face because then they know who $i$ am and councellors on here don't know who u r' [you are] Niffy234, 16 years

“...Online, i feel more confident in saying how i truly feel, and $i$ can say ALL thats going on with me... "Niffy234, 14 years 
Safety and Freedom

One of the tensions exposed by the research was around Safeguarding. In the UK, Safeguarding refers to statutory Government guidance (Department for Education 2013) on protecting and preventing harm, together with maintaining and promoting the welfare of children and young people.

In my research, only one respondent referred specifically to a practitioner's need to engage with safeguarding young people at risk. Young people $(90 \%)$ predominantly used the word 'safe' in terms of being able to say openly what their experiences were, not 'safe' as in needing to be 'guarded' against. What cannot be discounted though is the impact of the 'disinhibition effect' (Suler 1998) and how this reduction in social inhibitions that apply in faceto-face communications may also contribute to young people's sense of safety and freedom online.

"..I can talk about really bad things, more freedom to say what I want to say..." echo reflection, 16 years.

" l'd probably want a guarantee that no matter what we talk about, it stays between us and only us...no face to face counsellor in the world would offer that... so it has to be online" Floyd, 17 years

It appeared that young people were free to say all they needed to say and were not inhibited by the presence of the other. Does cyberspace therefore, offer what appears to be the lack of a symbiotic relationship between the young people and their parents (others) and this is experienced as Freedom? Not being able to 'see' the counsellor, the young people feel a sense of freedom to express and take care of their own needs rather than having to take care of and adapt to the other in order for the other to take care of them in return.

"if you are talking to someone who doesn't know you, they you won't judge you and they won't worry about you therefore there are fewer feelings of guilt concerning the subject" Katiiee, 17 years

“..whereas online it kinda feels like youre talking to the computer.. "primarytimer123

“..easier to say online how you truly feel, safer not being judged" noname, 23 years

Reeves (2010,) says, "there is no 'right' or 'wrong' position to take regarding suicide - just your own position" (p. xii), but is this possible with vulnerable young people? Anonymity raises questions and concerns for professionals with regards to safeguarding. How do you safeguard an anonymous young person in cyberspace and how do you make cyberspace 'safe' and if you do would young people use it to the degree to which they do? “...online it feels safer to open up.." Nelly21, 21 years

"..I can talk about really bad things, more freedom to say what I want to say..." cloudburst123, 16 years

Safety and Freedom were also expressed in relation to the lessening impact that 'suicide talk' in cyberspace has on the other, due to their absence and hence a lesser impact on the young person (15\%). Whether this is positive is debatable.

“...you cnt [can't] see there [their] reaction and they cnt [can't] see urs [yours], it makes the impact easier to deal with.."SUnshiNe, 17 years

“. you don't have to look at the person.." exfactorr, 16 years

It would appear from these comments though, that the freedom expressed may be freedom from judgment. Young people do not want to be judged for experiencing and expressing such vulnerabilities.

Confidentiality

Confidentiality is a strongly held professional responsibility based on ethical principles and professional codes of practice. Breaching of confidentiality for any practitioner working with vulnerable young people at risk is also a professional and ethical responsibility. While many vulnerable young people have been removed from harm through UK current Safeguarding procedures, there seemed to be a number of young people in my research $(25 \%)$ who appeared reluctant to discuss faceto-face their inner turmoil due to their perceived belief that this would lead to a breach of their confidentiality. If young people are requiring or demanding confidentiality then anonymity in cyberspace preserves and provides it and young people know this.

" l'd probably want a guarantee that no matter what we talk about, it stays between us and only us...no face to face counsellor in the world would offer that... so it has to be online" Floyd, 17 years

"...online there is more confidentiality therefore more freedom to say what you want to say", ticktac, 15 years

Yet what young people call confidentiality could also be interpreted as an inability of the other to take action. In the anonymous environment of cyberspace, as a practitioner you are unable to act; you have little choice but to keep confidentiality!

"..i touched on my suicidal feelings with my f2f [face-toface] counsellor, she told me she had to pass it on and I had to persuade her into thinking I would never do it :/ [symbol for facial expression]" rainbowgirl, 16 years

'..if I though [thought] for a second that by talking to a counsellor, action would be taken, I would definitely not talk to one..." chillie, 18 years 
Control

Widdowson (2008) argues that because of the "massive neurological organisation" (p.143) taking place during adolescence, adolescents have limited neurological capacity and hence lack ability to successfully regulate or control their intense and difficult emotions. In cyberspace young people appear to have more of this capacity then they do in their offline world. They appear to be utilizing a means of support that helps them to manage and contain their emotions and believe, rightly or wrongly, that they have control of both themselves and, importantly, the other. The young people can indicate when feeling overwhelmed that enough is enough, both intrapsychically and interpersonally, simply by logging off and leaving their distress online!

"...online if you feel worried or upset or anything you can just close down the computer really quick and make the person go away...online you can be more in control ..." JAir, 17 years

"...online feels safer...if you panic you can turn the conversation easier" $K 9,16$ years

"...if I spoke face to face to someone about some of the stuff, well l'd probably just keel over with embarrassments, nerves, tears you name it!: echo reflection, 16 year

"..there is less emotions due to the fact that you can't see the other person's emotions.." tiny luv, 15 years

Winnicott (1971) described adolescence as the "death of someone" and that through the process of maturation and the emerging into adulthood "there is to be found death and personal triumph" (p.145). Logging off seen from this perspective takes on another dimension. Could this 'death of someone' be the death of the practitioner containing the projected distress? This would be a preferable option for distressed and vulnerable young people?

A noticeable emotion regulated by the young people in cyberspace appeared to be shame; Tilney (1998) writes of it as "self-judgment for some public display of inadequacy" (p. 114). Cyberspace allows young people to be vulnerable in the 'presence' of the other without being seen to be so.

"I feel ashamed or embarrassed talking f2f [face-t0-face]" confusedgurl 16 years

Kaufman (1989) states that phenomenologically, to feel shame is to feel seen in a painful, diminished sense.

“..don't like people seeing me cry.." snow, 16 years

Liebert et al (2006) asks whether cyberspace offers relief to those who are especially sensitive to the presence of others, those who have experienced emotional trauma, social marginalization, or misjudgement from others, those who may therefore need to communicate without the fear of the other's reaction or their imagined condemnation. This would certainly concur with Tomkins (1978) who stated, "shame is the affect of indignity, transgression and of alienation" (p.135). How creative then of young people to have found a way of dealing with shame inducing activity.

"..watching their face as they take in what you say is what I like not seeing......disgust or anger towards your story... echo reflection, 16 years

Echo reflection expected "disgust and anger". In this she appears to be transferring her real life expectations into cyberspace via the computer. Hargaden and Sills (2002) speculate on whether there is any relationship free from transference. While the authors were referring to relationships in real life, it would appear that transference is alive and well and living in cyberspace too. Suler (1998) describes cyberspace as a possible "transitional space .an extension of the individual's intrapsychic world" (p.1) - a psychological space that can stimulate the process of projection, acting out and transference relating.

\section{Limitations of the study}

The results exposed the limitations of the study. The young people who replied were already using the online environment so were likely to have decided their preference already. More research is needed to get the views of suicidal young people who are using a face-toface or telephone service. Ideally, research is needed to explore the preferences of those who have used online, face-to-face and telephone so that a comparison can be conducted. More studies would also overcome the limitation of the relatively small $n$ of 24 .

Other factors are the identity of the respondents and how genuine their suicidal ideation was. We assume they were the ages and gender they said they were when joining the website but there is no way to check that.

\section{Conclusion}

The young people who responded to the research question indicated that they prefer the online environment when discussing their suicidal ideation and that in cyberspace they have found a space where they feel safe to discuss their turmoil in complete confidence.

However, it is the very thing they credit for creating this 'safe' space, anonymity, which causes major concerns. The anonymous online environment challenges professionals to hear young people in a different way, a way directed and dictated by them. It is we, as professionals and organisations who are being challenged in how we individually and procedurally 
respond and interact and are thus engaged in the ultimate learning from the patient (Casement 1985).

The implications for safeguarding our most vulnerable and distressed young people at this critical time are significant. How can we reconcile our duty of care and to protect with the safety they clearly see as provided by the anonymous online environment? If young people's preference for discussing 'big' problems is via the anonymous environment of cyberspace, is this an indictment of current UK Safeguarding procedures that young people are creatively bypassing by using cyberspace?

Another conclusion is that some young people at their most distressed appear to not want a reaction from us or for us to engage in action. Many simply want to be listened to by another willing to go there with them other, someone who will simply ask the questions "How do you hurt?" and "How can I help?"

Sally Evans Certified Transactional Analyst (Psychotherapy) can be contacted on se@sally-evans.co.uk

\section{References}

Ayres, A. (2006). The Only Way is Out? A Consideration of Suicide. Transactions, The Journal of the Institute of Transactional Analysis: 4. 4-13

Braun, V. \& Clarke, V. (2006). 'Using Thematic Analysis in Psychology', Qualitative Research in Psychology, 3:2, 77-101

Befrienders Worldwide (2013) Suicide Statistics: http://www.befrienders.org/suicide-statistics accessed 7 May 2013

Casement, P. (1985). On Learning from the Patient. London: Routledge

Childline (2008) Survey In TherapyToday Children "too embarrassed to talk about problems" 19: 5:

http://www.therapytoday.net/article/show/356/ accessed 7 May 2013

Cooper (2013) School Based Counselling in UK Secondary Schools: A Review and Critical Evaluation www.iapt.nhs.uk/silo/files/school-based-counselling-review.pdf accessed 10 April 2013

Cornell, W. F. (2008). Thinking about Suicide: Standing in the Face of Despair. Explorations in Transactional Analysis, The Meech Lake Papers. Pleasanton, California. TA Press.

Department for Education (2013) Children and Young People: Safeguarding children

http://www.education.gov.uk/childrenandyoungpeople/safeguar dingchildren accessed 7 May 2013

Hargaden, H \& Sills, C, (2002). Transactional Analysis, A Relational Perspective. Sussex: Brunner-Routledge

Henley, T. (2009) The Working Alliance in Online Therapy with Young People: Preliminary Findings. British Journal of Guidance and Counselling 37:3, 257-269

Jacobs, J. (1978). Adolescent Suicide. New York: Irvington Publications

Kaufman, G. (1989). The Psychology of Shame. New York: Springer Publishing Company Ltd.
Kidshelpline (2011) Overview

http://www.kidshelp.com.au/upload/22918.pdf.

Accessed 5 September 2013

King, R. Bambling, M. Lloyd, C. Gomurra, R. Smith, S. Reid, W. Wegner, K. (2006). Online Counselling: The motives and experiences of young people who choose the Internet instead of face to face or telephone counselling. Counselling and Psychotherapy Research. 6:3,169-174

Leenars, A (2020) Review: Edwin S Shneidman on Suicide Suicidology Online 1:5-18 www. suicidologyonline.com/pdf/SOL-2010-1-5-18.pdf accessed I July 2013

Levin, P. (1982). The Cycle of Development. Transactional Analysis Journal. 12:2, 129-139

Liebert. T, Archer. J, \& Munson. J. (2006). An exploratory study of client's perceptions of Internet counselling and the therapeutic alliance, Journal Of Mental Health Counselling, 28. 69-84

Little, R. (2009). Understanding the Psychodynamics of Suicidal Clients: Exploring Suicidal and Presuicidal States. Transactional Analysis Journal, 39, 3. 219-228

McLeod, J. (2001). Qualitative Research in Counselling and Psychotherapy. London: Sage Publications

Office of National Statistics (2011) Suicide in the United Kingdom.http://ons.gov.uk/ons/rel/subnationalhealth4/suicides-in-the-united-kingdom/2011/index.html, accessed 8 May 2013

Palfrey, J \& Gasser, U. (2008) Born Digital: understanding the first generation of digital natives. New York: Basic Books

Reeves, A. (2010) Counselling Suicidal Clients (Therapy in Practice). London: Sage Publications

Shadbolt, C. (2009). Sexuality and Shame. Transactional Analysis Journal, 39:2 163-172

Shneidman, E. (1994a). Clues to suicide reconsidered.Suicide and Life-Threatening Behavior, 24,395-397

Suler (1998) The Psychology of Cyberspace http://users.rider.edu/ suler/psycyber/psychspace.html accessed 26 Sep 2012

Tilney, T. (1998). Dictionary of Transactional Analysis. London: Whurr Publishers Ltd

Tomkins, S. S. (1987). Shame. In D. L. Nathanson (Ed), The Many Faces of Shame New York: Guildford Press 131-166

Turkle, S. (2011). Alone Together. New York: Basic Books

White, T (2011). Working with Suicidal Individuals. A Guide to Providing Understanding, Assessment and Support. London: Jessica Kingsley Publication

Windfuhr KL, While DT, Hunt IM, Turnbull P, Lowe R, Burns JM, Shaw J, Appleby L, Kapur NN. (2008). Suicide in juveniles and adolescents in the United Kingdom. Journal of Child Psychiatry and Psychology, 49, 1165-1175

World Health Organisation (2009) Suicide Prevention (SUPRE) http://www.who.int/mental health/prevention/suicide/suicidepre vent/en/ accessed 1 July 2013

Widdowson, M (2008). Working with Adolescents. In K. Tudor (Ed.) The Adult is Parent to the Child. Transactional Analysis with Children and Young People. Dorset: Russell House Publishing Ltd 132-150

Winnicott, D.W. (1971). Playing and Reality. London: Routledge 